Disponível em

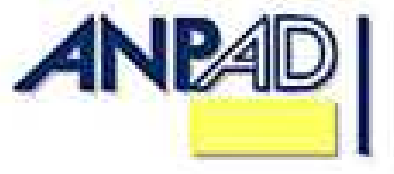

http://www.anpad.org.br/rac

RAC, Rio de Janeiro, v. 17, n. 2, art. 4, pp. 198-217, Mar./Abr. 2013

$(\mathrm{coc}) \mathrm{EY}-\mathrm{NC}$

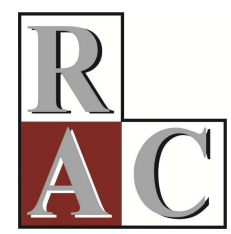

\title{
O Pós-estruturalismo e os Estudos Críticos de Gestão: da Busca pela Emancipação à Constituição do Sujeito
}

\section{Post-structuralism and Critical Management Studies: the Desire for Emancipation and the Constitution of the Subject}

Eloisio Moulin de Souza E-mail: eloisiomoulin@gmail.com

Universidade Federal do Espírito Santo - CCJE/UFES Av. Fernando Ferrari, 514, CCJE/Departamento de Administração, 29075-910, Vitória, ES, Brasil.

Susane Petinelli Souza

E-mail: susipetinelli@gmail.com

Universidade Federal do Espírito Santo - CCJE/UFES Av. Fernando Ferrari, 514, CCJE/Departamento de Administração, 29075-910, Vitória, ES, Brasil.

Alfredo Rodrigues Leite da Silva

E-mail: alfredoufes@gmail.com

Universidade Federal do Espírito Santo - CCJE/UFES Av. Fernando Ferrari, 514, CCJE/Departamento de Administração, 29075-910, Vitória, ES, Brasil. 


\title{
Resumo
}

Os Estudos Críticos em Gestão (ECG) são formados por bases epistemológicas distintas. Contudo, haveria algum ponto em comum que fosse capaz de dar um status de campo de estudo aos ECG? Alguns autores afirmam que a busca pela emancipação seria uma característica comum às correntes de pensamento que fazem parte dos ECG. Diante desse panorama, este artigo problematiza se a emancipação realmente é uma característica presente no movimento pós-estruturalista, enfocando principalmente as possíveis diferenças entre o pós-estruturalismo e a Teoria Crítica sobre esse tema, bem como analisando quais as possíveis distinções existentes entre autores pós-estruturalistas relacionadas à emancipação e à subjetividade. Para tanto, realizou-se uma pesquisa bibliográfica em estudos que discutem as principais características dos Estudos Críticos em Gestão. Conforme será descrito, o pós-estruturalismo deixa claro que pretende romper com a dicotomia existente na concepção de sujeito, na qual, em um polo, encontra-se um sujeito completamente autônomo (sujeito individual) e, no outro, um sujeito determinado pelo social (sujeito coletivo), rompendo com a dicotomia agência versus estrutura. Entende-se que emancipação é um ponto-nodal entre os Estudos Críticos em Gestão e não somente uma característica comum. Nesse sentido, o que existem são emancipações no plural, pois há diferenças conceituais entre e dentro das abordagens dos Estudos Críticos em Gestão que têm implicações diretas nos conceitos de universalidade, subjetividade e emancipação, bem como em suas formas de ação política.

Palavras-chave: emancipação; pós-estruturalismo; sujeito; estudos críticos em gestão.

\begin{abstract}
Critical Management Studies have distinct epistemological bases. However, is there something in common that could the study field status? Some authors suggest that the quest for emancipation is be a common feature in currents of thought that are part of the Critical Management Studies. Thus, this article questions whether emancipation is really a characteristic feature of the poststructuralist movement, focusing mainly on the possible differences between post-structuralism and Critical Theory as regards this topic, as well as analyzing possible distinctions between poststructuralist authors related to subjectivity and emancipation. Therefore, we performed a bibliographical research of studies that discuss the main characteristics of Critical Management Studies. Poststructuralism clearly attempts to break with the subject's agency vs. structure dichotomy; where a completely autonomous subject (individual subject) is at one pole, and another socially determined subject determined (collective subject) is at the other. Emancipation seems to be not merely a common feature in Critical Studies, but also a nodal point. In this sense, emancipations only exist in the plural, because there are conceptual differences between and within the approaches to Critical Management Studies which have direct implications on the concepts of universality, subjectivity and emancipation, as well as on their forms of political action.
\end{abstract}

Key words: emancipation; post-structuralism; subject; critical management studies. 


\section{Introdução}

Fournier e Grey (2006) apontam um crescente interesse e uma popularização dos Estudos Críticos em Gestão (ECG), denominado em solo inglês de Critical Management Studies (CMS). Os Estudos Críticos em Gestão englobam uma grande diversidade de trabalhos que possuem diferentes bases epistemológicas. Nesse sentido, Adler, Forbes e Willmott (2007) apontam como recursos teóricos dos ECG as Teorias Estruturais Orientadas, a Sociologia Clássica, o Marxismo, a Teoria do Processo de Trabalho, a Teoria Crítica da Escola de Frankfurt, o Pragmatismo e o Interacionismo Simbólico, o Pós-estruturalismo, o Feminismo e as Teorias Ambientais.

Adler et al. (2007) salientam que seria um erro atribuir muita unidade entre as diversas abordagens teóricas que formam o campo dos ECG devido à diversidade de pensamento existente dentro dos ECG, diversidade esta também apontada por Faria (2009a). Entretanto, apesar dessa diversidade, Adler et al. (2007) enfatizam que é possível discernir a existência de um senso largamente compartilhado de propostas entre as teorias contidas nos ECG que o consolidam como um campo próprio de estudo. Mandiola (2010) também afirma que os ECG não são um corpo coeso de saber; contudo, para a autora, sua diversidade inerente vem de seus diferentes backgrounds teóricos, afirmando ser essa diversidade um dos principais aspectos positivos dos ECG. Segundo a autora, os ECG são um significante vazio, um lugar de pluralidade e antagonismo que vai além dos relatos sedimentados sobre críticas e resistências. A teorização dos ECG como um significante vazio é importante, pois só assim poderá prover o significante ECG com um conteúdo inteligível e positivo. Como significante vazio, deve-se entender a capacidade dos ECG em acomodar muitas abordagens diferentes sobre um mesmo rótulo. Dessa forma, observa-se que os Estudos Críticos em Gestão (ECG) são uma grande colcha de retalhos, colcha esta formada por bases epistemológicas distintas. Contudo, qual seria a linha capaz de costurar e alinhavar todos esses retalhos e dar aos ECG o status de campo de estudo na administração? Os trabalhos de Davel e Alcadipani (2003), Alvesson e Willmott (1996), Parker e Thomas (2011), Adler et al. (2007), Grey e Willmott (2005) e Fournier e Grey (2006) intentaram responder essa questão.

Nesse sentido, Davel e Alcadipani (2003), Alvesson e Willmott (1996) e Fournier e Grey (2006) concordam que, dentre outras características, os Estudos Críticos em Gestão buscam a emancipação e, sendo assim, emancipação seria uma característica comum a todas as correntes de pensamento que fazem parte dos ECG.

Apesar da ausência de amplo consenso sobre este tema, têm ocorrido diversos debates sobre emancipação nos ECG, pois a emancipação tem sido uma aspiração crucial para a filosofia crítica do hemisfério norte, filosofia esta que tem inspirado muitos autores dos ECG (Mandiola, 2010). Diante desse cenário, este artigo problematiza se a emancipação realmente é uma característica presente no movimento pós-estruturalista, enfocando-se principalmente as possíveis diferenças entre o pósestruturalismo e a Teoria Crítica sobre esse tema, bem como analisa quais as possíveis distinções existentes dentro do próprio pós-estruturalismo, relacionadas à emancipação e à subjetividade. Por que se escolheu o pós-estruturalismo como cerne central desta análise? Devido ao pós-estruturalismo ser constantemente alvo de críticas direcionadas à sua falta de engajamento na promoção de mudança social e emancipação, conforme defendem Parker e Thomas (2011). O intuito é colocar em questão generalizações simplistas e contribuir para o rigor epistemológico na área organizacional. Para tanto, realizou-se uma pesquisa bibliográfica em estudos que trabalham e discutem as características dos Estudos Críticos em Gestão (ECG), bem como obras de pensadores pós-estruturalistas que fundamentam parte desses estudos.

Ressalta-se que a originalidade deste artigo é devida à carência deste tipo de análise nos Estudos Organizacionais brasileiros, principalmente pela falta de um olhar mais amplo do movimento pósestruturalista, no qual se tragam à tona conceitos de autores pós-estruturalistas ainda não explorados nos estudos organizacionais brasileiros, dentre eles Laclau, Mouffe e Guattari, conforme pesquisa realizada na plataforma Spell. 
Para desenvolver a referida discussão, este artigo inicia-se apresentando os principais argumentos desenvolvidos por autores organizacionais que defendem a existência de características comuns que formariam os Estudos Críticos em Gestão (ECG). Em seguida, são debatidos aspectos relacionados ao pós-estruturalismo e é analisada a noção de sujeito contida nessa perspectiva e a sua possível aderência, ou não, ao projeto emancipatório.

\section{Estudos Críticos em Gestão (ECG) e sua Relação com o Projeto Emancipatório}

Segundo Mandiola (2010) e Adler et al. (2007), os Estudos Críticos em Gestão (ECG) tornaram-se um campo de estudo formalizado na área de gestão com a publicação, em 1992, do livro de Alveson e Willmott, intitulado Critical Management Studies. Entretanto, Adler et al. (2007) deixam claro que não se pode falar que essa obra seja a origem dos estudos críticos em gestão, pois essa tradição vem tanto da crítica weberiana da burocracia e do capitalismo corporativo quanto da Teoria do Processo de Trabalho, que salienta a exploração dos trabalhadores pelos empregadores, como, por exemplo, o trabalho de Braverman (1987). Entende-se, como campo de estudo, uma área de concentração acadêmica que se constitui pela criação de uma comunidade de cientistas que dialogam entre si, buscando a elaboração de um código de comunicação próprio por meio de pesquisas (André, 2010). Dessa forma, a constituição de congressos, pesquisas e periódicos para o debate entre os pesquisadores demonstra a consolidação, ou não, de um campo de estudo.

Para os ECG, a gestão não é uma atividade meramente técnica, conforme aponta Hales (1986). Segundo o autor, a gestão é uma função de status para um determinado grupo, que exerce papel de manutenção e formas de controle da organização do trabalho, e preserva disparates no poder socioeconômico nas instituições. A partir desse entendimento, o autor compartilha com Alvesson e Willmott (1996) a ideia de que, quando a gestão é vista como uma atividade técnica, uma cegueira é colocada sobre as diversas relações sociais das quais o próprio trabalho dos gestores depende. Para Alvesson e Willmott (1996), representar a gestão como uma atividade técnica é uma tentativa de criar a ilusão de neutralidade. O combate à ideia de que gestão é uma técnica neutra e, portanto, desprovida de relações de poder, é o principal ponto defendido pelos ECG. Os ECG pretendem romper com o conceito de neutralidade gerencial, trazendo para o campo organizacional o estudo de aspetos sociais e políticos.

Ao arguirem sobre as principais características que estariam contidas nos ECG, ressaltando-se que Alvesson e Willmott (1996) denominam estes estudos de Critical Management Theory (CMT), estes autores apontam para os seguintes elementos: (a) gestão concebida como prática social; (b) gestão não vista como uma prática objetiva e imparcial; (c) ênfase no estudo das tensões existentes no processo de gestão, ou seja, estudo das relações de poder; (d) tentativa de iluminar e transformar as relações de poder que oprimem os trabalhadores nas organizações; e (e) intenção emancipatória.

Parker e Thomas (2011), ao debaterem o que significa crítico, afirmam que o termo crítico não tem apenas um significado, pois existem diferentes histórias e contextos para os trabalhos críticos nas diferentes ciências humanas e sociais. Entretanto, eles esclarecem que existe algo comum e necessário para que trabalhos sejam considerados críticos, que é o reconhecimento de que conhecimento é político e não algo neutro, bem como a presença de reflexividade. Grey e Willmott (2005) concordam com Parker e Thomas (2001), que afirmam a reflexividade e a problematização da hierarquização dos saberes pelas relações de poder são características comuns aos ECG, contudo, também incluem o construcionismo como ponto de aproximação entre as diversas correntes dos ECG.

Adler et al. (2007) denominam os ECG de Critical Management Studies (CMS), afirmando que os CMS acomodam diversas tradições teóricas. Assim, o termo crítico não sinaliza o compromisso em particular com alguma corrente teórica de pensamento, como, por exemplo, a Teoria Crítica da Escola de Frankfurt. Dessa forma, os ECG são formados por um corpo heterogêneo, corpo este que compartilha alguns temas em comum, mas que nunca é inteiramente consistente. 
Fato também constatado por Faria (2009a), ao dividir os estudos organizacionais críticos em quatro grandes áreas: Teoria Crítica Frankfurtiana, Teoria Crítica em Estudos Organizacionais (estudos marxistas sobre a centralidade do trabalho), Critical Management Studies (trabalhos de Alvesson, Deetz e Willmott), e Análise Crítica em Estudos Organizacionais (análises críticas não marxistas e não frankfurtianas, como pós-estruturalismo, análises institucionais, simbolismo e pósmodernismo). Faria (2009a) não caracteriza a CMS como sendo a grande categoria dos estudos críticos que abarcaria todas as demais abordagens, nem como uma abordagem crítica, denominando-a de acrítica.

Adler et al. (2007) enfatizam que o que os ECG têm em comum é um profundo ceticismo em relação à moralidade e à sustentabilidade social e ecológica prevalecentes nas formas de gestão e organização das empresas. Para os autores, existe uma crença compartilhada nos ECG de que a gestão das empresas modernas é guiada por uma meta míope e estreita de lucro, ao invés de por interesses da sociedade como um todo.

Em outra tentativa de caracterizar os ECG, Fournier e Grey (2006) salientam que eles são formados por uma pluralidade de tradições intelectuais que possuem em comum três características: (a) não preocupação com questões performativas relacionadas às organizações; (b) compromisso com a desnaturalização; e a (c) reflexividade. Para Fournier e Grey (2006), o que difere uma perspectiva de análise crítica para uma não crítica é a forma como a abordagem crítica invoca noções de poder, controle e equidade em seus estudos, em detrimento de questões relacionadas à eficiência, efetividade e lucratividade. Em relação à desnaturalização, os autores sugerem que os ECG não são uma entidade estática e, por isso, a teoria organizacional sempre está sofrendo mudanças e revisões sobre a natureza da prática gerencial e das próprias teorias organizacionais. Desta forma, os ECG estão envolvidos em uma crítica perpétua da teoria organizacional, crítica esta que inclui a própria ECG em sua ênfase de reflexividade. Portanto, para Fournier e Grey (2006), os ECG são um projeto político no sentido em que objetivam desmascarar as relações de poder presentes na vida social e organizacional. Os autores afirmam que a noção de emancipação está presente em todas as tradições intelectuais que formam os ECG. Davel e Alcadipani (2003, p. 74), ao pesquisarem a produção científica brasileira de ECG na década de noventa, denominados por eles de Estudos Críticos em Administração, afirmam que existem três parâmetros para se identificar um estudo como pertencente aos ECG: "(1) promulgação de uma visão desnaturalizada da administração, (2) intenções desvinculadas da performance e (3) um ideal de emancipação". Para Davel e Alcadipani (2003), as tradições intelectuais que comporiam o quadro dos ECG seriam as tradições marxistas e neo-marxistas da Escola de Frankfurt; o pós-estruturalismo, o pós-modernismo, o pós-colonialismo e as teorias feministas. Os autores explicam, ainda, que todos os ECG têm uma intenção emancipatória, pois "procuram enfatizar, nutrir e promover o potencial da consciência humana para refletir de maneira crítica sobre as práticas opressivas, facilitando, assim, a extensão dos níveis de autonomia e responsabilidade das pessoas" (Davel \& Alcadipani, 2003, p. 75).

Assim, conforme exposto, não há um consenso amplo sobre qual seriam as características comuns que marcariam uma tradição teórica como pertencente aos ECG. Contudo, apesar da falta de unanimidade, pode-se verificar que emancipação, reflexividade e não neutralidade do conhecimento administrativo são as características mais citadas.

Alvesson e Willmott (1996) e Fournier e Grey (2006) também defendem que a busca pela emancipação é uma característica presente em todos os ECG, enfatizando que o pós-estruturalismo é uma das tradições intelectuais presente nos ECG e, assim sendo, compartilha dessa busca emancipatória. Em um artigo denominado Critique in the name of what: postmodernism and critical approaches to organization, publicado na Organization Studies, Parker (1995) afirma que qualquer ideia que abandona o projeto emancipatório e sua possibilidade de verdade e progresso é algo perigoso e potencialmente inútil para ser adotado por qualquer teorista crítico em organizações. Parker (1995) defende que emancipação é um conceito que deve estar presente em todos os ECG, constituindo-se como divisor do que é, ou não, um estudo crítico.

Contudo, o que seria emancipação? Como os ECG abordam esse conceito? O pósestruturalismo, com sua fragmentação do sujeito, com sua fuga para metanarrativas emancipatórias e 
universalidades essencialistas, seria capaz de promover ação política emancipatória? Aliás, a descrença pós-estruturalista na existência de verdade e progresso não minaria por si só qualquer projeto emancipatório? A próxima seção deste artigo pretende iniciar o debate sobre essas questões por meio da análise da Teoria Crítica Frankfurtiana.

\section{Emancipação na Teoria Crítica}

O significado do termo emancipação não é idêntico entre os autores dos ECG, além do que muitos deles não utilizam este termo em suas obras quando se referem a ideais libertários. Assim, esta sessão do artigo irá discutir o conceito de emancipação dentro da Teoria Crítica (Teoria Crítica Frankfurtiana e Estudos Marxistas sobre a centralidade do trabalho).

Braverman (1987) foi um dos pioneiros nos estudos marxistas sobre a centralidade do trabalho, também conhecida como Teoria do Processo de Trabalho (TPT). Os estudiosos dessa corrente usam elementos chaves do Marxismo para defender que o mercado não pode regular sozinho o trabalho, buscando emancipação e maior autonomia do trabalhador. Adler et al. (2007) esclarecem que a TPT fundamenta-se na crença de Gramsci de que a hegemonia de um grupo sobre outro nasceu dentro das fábricas, permitindo a existência de uma relação entre a TPT e a Escola de Frankfurt. Existe, no processo emancipatório da classe trabalhadora pelo Marxismo, um essencialismo do sujeito que é absorvido por uma estrutura de classes em que todas as dimensões de sua vida são reduzidas à sua condição de classe, promovendo uma concepção unificada do indivíduo (Mendonça, 2008).

Faria (2009b, p. 421) esclarece que a Teoria Crítica tem uma orientação para a emancipação, pois a

Teoria Crítica em geral, no sentido que lhe empresta Horkheimer, pretendia denunciar a repressão e o controle social a partir da constatação de que uma sociedade sem exploração é a única alternativa para que se estabeleçam os fundamentos da justiça, da liberdade e da democracia.

Para Alvesson e Willmott (1992), os trabalhos de Fay, Fromm, Habermas, Adorno, Horkheimer e Marcuse seriam exemplos de teóricos críticos da Escola de Frankfurt que contribuem para a emancipação. Para os autores, uma crença fundamental da Teoria Crítica é que as ciências sociais podem e devem contribuir para liberar as pessoas de tradições restritivas desnecessárias, de ideologias, de relações de poder, das formações de identidades, ou seja, de tudo aquilo que inibe e distorce as oportunidades de autonomia.

Alvesson e Willmott (1996) salientam que a visão de um homem autônomo, que se autodetermina, manifesta a ideologia do individualismo em que se privilegia o individual ao invés dos processos sociais. A visão autônoma esconde que o homem é formado por relações de poder e, assim o sendo, sua visão de mundo, preferências e opiniões estão presas em uma teia social, não permitindo que ele se liberte dessa teia. Nessa ótica, a emancipação seria o movimento de libertação do homem de ideologias que seriam prejudiciais a ele.

Segundo Paula (2009), dentro da perspectiva da Teoria Crítica Frankfurtiana, a ideologia não pode ser vista como falsa consciência. A visão de ideologia como falsa consciência está presente no marxismo ortodoxo vulgar e não na Escola de Frankfurt. Para Paula (2009), ideologia é a própria realidade que homogeneíza o mundo. Nesse sentido, a autora afirma que existe um sistema de dominação que opera sobre as pessoas, contudo, não se pode afirmar que na perspectiva frankfurtiana as pessoas têm falsa consciência de que as impediria de resistir, ou que há um grupo que promove a dominação sobre os demais. Para os frankfurtianos, "por detrás da razão há o sujeito, que por meio de sua autonomia pode restituir sua face emancipatória" (Paula, 2009, p. 11). 
Faria e Meneghetti (2007) afirmam que a Teoria Crítica acredita que existe uma ideologia dominante que torna parcial a consciência dos indivíduos em relação ao social, e que a emancipação é a busca constante de autonomia do indivíduo em relação à sociedade, fomentada pela possibilidade de criação da sua própria história, consciente de sua existência. Como consciência, os autores entendem o homem estar ciente de si mesmo, das emoções, dos sentimentos e percepções, em que a fragmentação da consciência impossibilita o surgimento da consciência coletiva emancipada. Destaca-se que Faria (2009b) esclarece que a Teoria Crítica combate o individualismo, entendido pelo movimento pelo qual o mundo deixa de ser coletivo para ser individual, bem como as diversas formas de dominação que inviabilizam a emancipação humana.

A importância da razão no processo emancipatório também está presente no Iluminismo/Humanismo, no qual a razão científica exercida por homens considerados iluminados promoveria a emancipação dos homens. Aliás, Alvesson e Willmott (1992) afirmaram que uma das crenças fundamentais da Teoria Crítica é que as ciências sociais tem o papel de libertar as pessoas das tradições, ideologias, relações de poder e identidades que inibem a autonomia do sujeito. Contudo, não seriam estes cientistas sociais também envoltos pela teia social e formados por relações de poder? A crença de que os cientistas sociais estão em uma posição privilegiada, remanifesta a crença na ciência e na razão como veículos promotores da emancipação, e cria um sujeito emancipado pela (con)sciência.

Contudo, apesar de valorizar a razão, como o fez o Iluminismo/Humanismo, a Teoria Crítica tem um entendimento específico dela. Fundamentando-se em Horkheimer, Faria (2009b) afirma que a razão instrumental não é capaz de guiar o homem em direção à emancipação. O progresso tecnológico, com sua racionalidade técnica, colabora para que ocorra uma aceitação não questionadora de outras formas de subversão da razão. Em função disso, Faria (2009b, p. 423) afirma que a Teoria Crítica, "pretende expressar a emancipação dos indivíduos e promover a conscientização crescente da necessidade de uma sociedade em que os interesses coletivos prevaleçam sobre os individuais, em que os indivíduos sejam sujeitos de sua própria história, escrevendo-a coletivamente".

Portanto, a razão e a capacidade de reflexão dos sujeitos é o que torna possível o processo emancipatório para os teóricos críticos. Contudo, concordando-se com Jermier e Clegg (1994), o pósestruturalismo não tem a mesma concepção de sujeito universal contida na Teoria Crítica, fato que contribui para que este não trabalhe com uma política emancipatória nos moldes da Teoria Crítica. Em função disso, para os autores, faz-se necessário repensar, dentro dos estudos organizacionais, o marxismo, o feminismo e outras estruturas essencialistas emancipatórias. Ou seja, devido ao conceito de sujeito contido no pós-estruturalismo, essa tradição de pensamento não entende o processo de geração de liberdade da mesma forma que a Teoria Crítica. Para legitimar tal afirmação, cabe esclarecer o entendimento de sujeito para o pós-estruturalismo.

\section{O Pós-estruturalismo e o Sujeito}

Segundo Peters (2000) e Souza (2012), existem semelhanças nas concepções de sujeito contidas no estruturalismo e no pós-estruturalismo. Conforme Newman (2005) salienta, o pós-estruturalismo emerge de dentro do estruturalismo e, assim sendo, tais semelhanças não são meros acasos. Contudo, apesar de compartilharem de uma visão próxima de sujeito, não se pode afirmar que ela seja idêntica. Para Newman (2005), o ponto central do estruturalismo é a ideia de que a experiência e a realidade são estruturadas através das relações com a linguagem, ou seja, nosso entendimento de nós mesmos e do mundo a nossa volta só pode ocorrer por meio de uma estrutura linguística externa que determina o significado. Em Saussure (1993), o significante é algo transparente, com existência a priori em relação ao sujeito, possuindo apenas um único significado possível. Estrutura é centro, unidade, consistência e estabilidade (Newman, 2005). 
Saussure (1993) entende a linguagem como um sistema linguístico de sinais formado de significante e significado. O sujeito do estruturalismo é um sujeito determinado pelas estruturas linguísticas em que identidade e experiência foram determinadas por uma estrutura externa, negando qualquer autonomia e capacidade de ação do sujeito. Assim, para o estruturalismo, o sujeito é algo unificado, possuindo uma identidade fixa e estável determinada e comandada pela estrutura. Newman (2005) alerta que, no estruturalismo, a estrutura é algo tão totalizante e determinante que pode ser vista como uma essência a-histórica, o que aproxima o estruturalismo do fundacionismo. Vale ressaltar que, para o pós-estruturalismo, o discurso não é uma estrutura, mas um acontecimento e, como tal, pertence à ordem histórica (Foucault, 1996).

Já para Willmott (2005), o pós-estruturalismo de Laclau e Mouffe (1987) rompe com o dualismo estrutura/ação, em que o processo de identificação torna-se relevante nesse rompimento. Isso ocorre porque a estrutura nunca é algo exaustivo para Laclau e Mouffe, e seu limite é hegemônica e precariamente assegurado, ou seja, há ausência de estruturalidade na estrutura e de um centro fixo que a comande. Em suas análises, os autores não privilegiam nem a estrutura, nem a agência. Apesar de Laclau e Mouffe (1987) acreditarem na existência de estrutura, a mesma não determina a ação do sujeito. A estrutura psíquica e ideológica é importante, contingenciando a inserção do sujeito. Laclau e Mouffe (1987) são influenciados pela perspectiva Lacaniana de sujeito, sendo que, inclusive, Laclau (2000a, 2000b) considera Lacan pós-estruturalista. Em seu momento contínuo de decisão, o sujeito é entrado (entered) para a inescapável, mas também indeterminada, produção dos limites imaginários e do real lacaniano. Willmott (2005) demonstra que o pós-estruturalismo de Laclau e Mouffe não é determinista, pois

For the moment of decision is conceived to exist in a relation of indeterminacy to the structure, it cannot be subsumed under any structural determinism'.... But neither is it autonomous of the structure since it is provoked by the 'failed strutuctural identity' ..., and 'what accounts as a valid decision will have the limits of an estructure (Laclau \& Mouffe, 1987 como citado em Laclau, 1996, p. 55-57).

Segundo Newman (2005), o pós-estruturalismo não rejeita o estruturalismo per si, mas o radicaliza. Para o autor, o pós-estruturalismo não rejeita a ideia de que a subjetividade é construída discursivamente por relações externas de linguagem, contudo, não acredita na existência de uma estrutura essencialista, questionando a unidade, a consistência e a estabilidade da estrutura. Newman (2005), influenciado por Laclau, fundamenta-se em Lacan para definir o sujeito como uma incompletude constituída e delimitada pela contingência social e pela indecidibilidade.

Segundo Newman (2005), esta desconstrução da estrutura acontece de duas formas no pensamento pós-estruturalista: (a) pensadores como Foucault e Deleuze sugerem que, ao invés de uma única e centralizada estrutura, existem múltiplas estruturas, discursos heterogêneos, relações de poder ou agenciamentos de desejos que são constitutivos da identidade, sendo estes imanentes ao campo social; (b) a segunda posição, que vem de Derrida e Lacan, enfatiza a estrutura, mas a vê como indeterminada, incompleta e instável. Derrida (1995) desconstrói o conceito de estrutura presente no estruturalismo. Para ele, toda estrutura é indeterminada, incompleta e instável. Dessa forma, o pósestruturalismo é antifundacionista, enquanto o estruturalismo é fundacionista. Ser antifundacionista significa que o pós-estruturalismo rejeita qualquer essencialismo, bem como a ideia de uma base moral e racional absoluta. Para Derrida (1995), existe um exterior para qualquer estrutura. Contudo, este exterior é incomensurável com seu interior, sendo esta incomensurabilidade a condição de sua emergência, ou seja, o exterior nem elimina, nem reafirma a estrutura, mas, ao invés disso, fá-la indecidível. Marchart (2007), ao criticar o fundacionismo, elucida que fundacionismo é uma teoria que assume que a sociedade e/ou a política são/é a base de princípios inegável e imune à revisão, localizado fora da sociedade e da política, produzindo determinismos, como, por exemplo, o determinismo do social pelo econômico. Contudo, Marchart (2007) considera o pós-estruturalismo pós-fundacionista e não antifundacionista.

Butler (2010), em sua crítica ao conceito de patriarcado presente nos estudos de gênero, esclarece a posição do pós-estruturalismo frente ao fundacionismo. Para ela, a presunção política da 
existência de uma base universal para o movimento feminista, que pode ser encontrada em uma identidade existente em diferentes culturas, "acompanha a ideia de que a opressão das mulheres possui uma forma singular, discernível na estrutura universal ou hegemônica da dominação patriarcal ou masculina" (Butler, 2010, p. 20). O patriarcado, constituído pelo feminismo com o objetivo de fortalecer a representatividade da pauta de reivindicação feminista, "motivou ocasionalmente um atalho na direção de uma universalidade categórica ou fictícia da estrutura de dominação, tida como responsável pela produção da experiência comum de subjugação das mulheres" (Butler, 2010, p. 21). Diferentemente de Laclau, Butler (2000b, 2010) considera a concepção de sujeito em Lacan estruturalista, dedicando sua obra na desconstrução do real lacaniano.

Além disso, a racionalidade e a moralidade não podem servir como fundamentos absolutos para o julgamento político e ético do sujeito (Torffing, 1999). Newman (2005) adverte que o pósestruturalismo não acredita que a prática política possa ser baseada em noções de sujeito autônomo e universal; ao invés, política deve ser vista como uma dimensão antagonista e imprevisível, que, ao mesmo tempo, constitui e desestabiliza seus limites. Para o pós-estruturalismo, sujeito e objeto se constituem mutuamente, não existindo primazia entre eles.

O sujeito autônomo, autoconsciente e livre, visto como fonte de razão e de todo conhecimento oriundo do cartesianismo-kantiano humanista, é colocado em cheque tanto pelo pós-estruturalismo quanto pelo estruturalismo. Contudo, o pós-estruturalismo substitui esta definição de sujeito por uma concepção de subjetividade descentrada, fragmentada. Um sujeito sem essência, sem origem (Peters, 2000). Calás e Smircich (1999) destacam que, no pós-estruturalismo, ocorre um descentramento do sujeito que, ao invés de ser origem, tem sua subjetividade embebida em um duplo movimento de produção e efeito, inserida em uma rede complexa de narrativas e práticas instáveis. Nesse sentido, os conceitos pós-estruturalistas de subjetividade contidos nas obras de Guattarri (1992), Foucault (2002a, 2002b, 2003) e Rolnik (1997a, 1997b) trazem esclarecimentos sobre a definição de sujeito para o pósestruturalismo.

Para Guattari (1992), a subjetividade é produzida por instâncias individuais, coletivas e institucionais. Contudo, para o autor considerar "a subjetividade sob o ângulo da sua produção não implica absolutamente ... voltar aos sistemas tradicionais de determinação do tipo infraestrutura material - superestrutura ideológica" (Guattari, 1992, p. 11). Segundo este autor, os diversos registros semióticos que concorrem entre si para a produção da subjetividade não têm e não mantêm relações definitivamente fixas e nem uma hierarquia obrigatória. "A subjetividade, de fato é plural, polifônica, para retomar uma expressão de Mikhail Bakhtin. E ela não conhece nenhuma instância dominante de determinação que guie as outras instâncias segundo uma causalidade unívoca" (Guattari, 1992, p. 11). Ainda de acordo com o autor, em determinados contextos sociais e semiológicos, a subjetividade se individualiza, ou seja, uma pessoa é vista como responsável por si mesma, e se posiciona em meio a diversas relações de alteridade regidas por aspectos familiares, culturais, jurídicos, locais, dentre outros. Em outros momentos e condições, a subjetividade se faz coletiva, motivo que não a torna exclusivamente social. Guattari (1992) enfatiza que não se deve entender o termo coletivo como somente uma multiplicidade que se desenvolve para além do indivíduo, junto ao socius, mas também como algo aquém da pessoa, junto a intensidades pré-verbais, derivado muito mais de uma lógica de afetos do que de uma lógica de conjuntos bem circunscritos. Nesse sentido, indivíduo e coletivo não são objetos dados, eles se constituem nas relações, por meio de processos que se formam no entrecruzamento de diferentes instâncias. Diante dessas considerações, pode-se afirmar que, para Guattari (1992, p. 15), subjetividade é "o conjunto das condições que torna possível que instâncias individuais e/ou coletivas estejam em posição de emergir como território existencial autorreferencial, em adjacência ou em relação de delimitação com uma alteridade ela mesma subjetiva".

Rolnik afirma que "As subjetividades, independentemente de sua morada, tendem a ser povoadas por afetos dessa profusão cambiante de universos; uma constante mestiçagem de forças delineia cartografias mutáveis e coloca em cheque seus habituais contornos" (Rolnik, 1997a, p. 19). A imensa variedade de universos que se miscigenam em cada subjetividade acaba tornando suas figuras e linguagens obsoletas muito rapidamente, levando-as a um empenho quase que permanente de reconfiguração (Rolnik, 1999). Nesse contexto, a subjetividade se descobre precária e incerta. 
Contudo, a autora salienta que a mesma globalização que atua como intensificadora das misturas e fragmenta as identidades também é produtora de kits de perfis-padrão para serem consumidos pelos sujeitos.

Existem possibilidades diversificadas de recomposição da subjetividade e de fuga de seus impasses repetitivos. A recomposição não se processa a partir de dimensões já existentes da subjetividade, dimensões estas cristalizadas em complexos estruturais, mas que procedem de uma criação e tornam-se um paradigma estético, criando-se novas modalidades de subjetivação. Desse modo, não estamos mais diante de uma subjetividade dada como um em si, mas diante de um processo de autonomização ou de autopoiese (Guattari, 1992): "Porém os grandes movimentos de subjetivação não tendem necessariamente para um sentido emancipador" (Guattari, 1992, p. 12). Para este mesmo autor, a história contemporânea demonstra um aumento das reivindicações de singularidades subjetivas, reivindicações autonomistas, questões nacionalistas e nacionais ambíguas, pois, ao mesmo tempo em que reivindica-se por maior liberdade, também se encarnam reterritorializações conservadoras de subjetividade. Como Rolnik (1997a) mesmo explica, as subjetividades tendem a ignorar as diferentes forças que as desestabilizam, organizando-se em torno de uma representação de si dada a priori, ou seja, em torno de uma referência identitária.

Rolnik (1997b), influenciada pelo pensamento de Deleuze, dá ênfase aos conceitos de dentro e fora no processo de produção subjetiva. Para ela, dentro e fora não são espaços separados, sendo indissociáveis, mas paradoxalmente inconciliáveis, no qual "o dentro detém o fora e o fora desmancha o dentro" (Rolnik, 1997b, p. 27). Mas o que significa dentro e fora para Rolnik (1997b, p. 27)? "O dentro é uma desintensificação do movimento das forças do fora, cristalizadas temporariamente num determinado diagrama que ganha corpo numa figura com seu microcosmo"; já o fora é "uma permanente agitação de forças que acaba desfazendo a dobra e seu dentro, diluindo a figura atual da subjetividade até que outra se perfile" (Rolnik, 1997b, p. 27). Assim, dentro é o território existencial que tem uma relação indissociável com as diversas forças do fora e ambos atuam conjuntamente na constituição da subjetividade, ou seja, "o movimento das forças é o fora de todo e qualquer dentro, pois ele faz com que cada figura saia de si mesma e se torne outra. $\mathrm{O}$ fora é um 'sempre outro do dentro', seu devir" (Rolnik, 1997b, p. 27).

A questão que Foucault levanta sobre o sujeito é muito similar a Guattari (1992), pois ele também pretende romper com a dicotomia sujeito individual versus sujeito coletivo. Foucault (2002b, p. 329) afirma que

nós descobrimos que a filosofia e as ciências humanas viviam sobre uma concepção muito tradicional do sujeito humano, e que não bastava dizer, ora com uns, que o sujeito era radicalmente livre e, ora com outros, que ele era determinado por condições sociais.

A problematização do sujeito está presente em toda obra de Foucault, contudo, ela se desdobra em dois momentos cruciais: (a) o primeiro arqueológico, associado a morte do sujeito, denominado por Canguilhem de esgotamento do cogito, presente em As palavras e as coisas: uma arqueologia das ciências humanas (Foucault, 1999); (b) o segundo momento apresenta-se a partir da escrita da História da sexualidade: o uso dos prazeres (Foucault, 1984), no qual Foucault redefine seu trabalho anterior, pretendendo analisar não mais as ideias nem os comportamentos, nem a sociedade e nem suas ideologias, mas as problematizações por meio das quais o sujeito se dá como possibilidade e dever de ser pensado e as práticas a partir das quais as problematizações se formam. Enfim, a "dimensão arqueológica da análise permite analisar as formas mesmas das problematizações; sua dimensão genealógica, sua formação a partir das práticas e suas modificações" (Foucault, 2002a, p. XXXVIII). Em seu momento arqueológico, Foucault aproxima sua concepção de sujeito com a do estruturalismo, apesar de não ser esta sua intenção. Já no momento genealógico/ético, Foucault consegue se libertar das influências estruturalistas tão presentes no meio acadêmico de sua época. Quando questionado em seu momento ético/genealógico, se o cuidado de si poderia ser visto como um processo de liberação do sujeito, Foucault (2004a) salienta que sempre desconfiou do tema geral de liberação, pois isto pode remeter à ideia de que existe uma natureza ou uma essência humana que foi mascarada, aprisionada ou 
alienada em processos históricos, econômicos e sociais que atuariam como mecanismos de repressão. Foucault (2004a, p. 265) afirma que, segundo essa

hipótese, basta romper esses ferrolhos repressivos para que o homem se reconcilie consigo mesmo, reencontre sua natureza ou retome contato com sua origem e restaure uma relação plena e positiva consigo mesmo. Creio que este é um tema que não pode ser aceito dessa forma, sem exame.

$\mathrm{Na}$ realidade, Foucault (2004a), em seu momento ético/genealógico, recusa-se a fazer uma teoria do sujeito, presentes, por exemplo, na fenomenologia e no existencialismo. Ele objetiva mostrar como o próprio sujeito se constitui nessa ou naquela forma determinada, como sujeito louco ou são, como sujeito trabalhador ou delinquente, por meio de práticas que são jogos de verdade e relações de poder. Para o autor, o sujeito não é uma substância, "é uma forma, e essa forma nem sempre é, sobretudo idêntica a si mesma" (Foucault, 2004a, p. 275). O que interessa para Foucault (2004a, p. 275) "é, precisamente, a constituição histórica dessas diferentes formas do sujeito, em relação aos jogos de verdade". "Há dois significados para a palavra sujeito: sujeito ao outro através do controle e da dependência, e ligado à sua própria identidade através de uma consciência ou do autoconhecimento" (Foucault, 2010, p. 278). Em ambos os significados, estão vinculadas uma forma de sujeição. Em relação à sua concepção de sujeito, Foucault (2004b, p. 291) afirma que

não há um sujeito soberano, fundador, uma forma universal de sujeito que poderíamos encontrar em todos os lugares.... Penso, pelo contrário, que o sujeito se constitui através das práticas de sujeição ou, de maneira mais, o termo 'práticas de liberação' não é sinônimo de liberação ou emancipação.

Para ele, a liberação existe, e cita como exemplo de liberação quando um povo colonizado procura se libertar do colonizador. Contudo, esta liberação não basta para definir as práticas de liberdade que em seguida serão necessárias "para que esse povo, essa sociedade e esses indivíduos possam definir para eles mesmos formas aceitáveis e satisfatórias da sua existência ou da sociedade política" (Foucault, 2004a, p. 266). Em função disso, Foucault (2004a, p. 266) afirma que é "por isso que insisto sobretudo nas práticas de liberdade, mais do que nos processos de liberação, que mais uma vez têm seu lugar, mas que não me parecem poder, por eles próprios, definir todas as formas práticas de liberdade".

Vimos anteriormente que a Teoria Crítica Frankfurtiana acredita que a fragmentação impossibilita o surgimento de uma consciência coletiva emancipada. Para ela, a fragmentação do sujeito tornaria qualquer forma de emancipação algo impossível e inviável. Também vimos que existem diversas possibilidades de subjetividades no pós-estruturalismo que têm em comum a fragmentação, a não centralidade da estrutura e a não unidade do sujeito. Assim, diante da fragmentação do sujeito anunciada pelo pós-estruturalismo, existe alguma possibilidade dessa tradição de pensamento promover alguma forma de emancipação do sujeito? Em outras palavras, há capacidade de ação política no pós-estruturalismo? A próxima sessão deste artigo pretende responder esta questão.

\section{Existe Intenção Emancipatória no Pós-estruturalismo?}

O pós-estruturalismo não acredita em grandes movimentos, em metanarrativas libertadoras ou em soluções universais para a questão do sujeito, fato já demonstrado na sessão anterior, quando, por exemplo, Guattari (1992) critica os grandes movimentos universais de subjetivação, afirmando que os mesmos não caminham para a emancipação. Em relação à universalidade, o pós-estruturalismo de Laclau traz contribuições interessantes sobre esse debate. Em sua teoria do discurso, Laclau (1996) aborda questões relacionadas à universalidade e à particularidade. Para ele, toda universalidade tem um conteúdo particular que se universaliza, pois o universal não tem um conteúdo a priori, mas é 
constituído a partir do particular. O universal sempre emerge a partir do particular, contudo, como um horizonte sempre incompleto, que costura uma identidade particular deslocada (Laclau, 1996).

Para Laclau (2000b), então, só há hegemonia se a dicotomia universalidade/particularidade for suprimida. Entretanto, universalidade existe apenas encarnada em alguma particularidade e toda particularidade só poderá ser política se tiver um efeito universalizante. Dessa forma, segundo o autor, toda relação hegemônica requer a produção de significantes vazios que mantenham a incomensurabilidade entre universal e particular, capacitando o universal de se representar em uma forma específica por meio de um significante vazio. Assim, o universal é sempre algo inacabado e incompleto, o que manifesta a sua impossibilidade.

Para Laclau (2000a), o significante vazio não é abundante e nem insuficiente, apenas marca os limites do processo de significação, ou seja, é um significante sem significado. Assim, toda estrutura discursiva abarca um sistema de diferenças, e os limites de um significante manifestam-se como rupturas de um sistema de significação. Enfim, o que permite a condição de possibilidade de um sistema, seus limites, constitui, simultaneamente, a sua condição de impossibilidade, pois é produtora de uma interrupção no sistema de significação, tendo em vista que todo limite produz exclusão. Assim, produz-se uma relação antagônica entre dois termos em que cada um deles impede o outro de atingir sua identidade plena. Enfim, identidade sempre será precária, instável e contingente, sendo necessário para sua existência incluir o outro pelo qual se delimita.

A visão de que o universal é sempre algo inacabado e incompleto faz Laclau e Mouffe (1987) afirmarem a impossibilidade de sociedade. Para eles, o social é articulação, pois a sociedade é impossível. Assim, "se o social não consegue fixar-se a si próprio em formas inteligíveis e instituídas de uma sociedade, o social apenas existe, contudo, como um esforço para constituir aquele objeto impossível" (Laclau \& Mouffe, 1987, p. 112). A esse esforço Laclau denomina de política. Nesse sentido, Laclau (2000b) evidencia sua intenção em não constituir uma universalidade pré-estabelecida ou uma característica racional do homem. Por isso, o universal é sempre vazio para este autor, ou seja, hegemonizado por algo contingente, particular, ou como diria ele (2000b, p. 59) "each Universal is the battleground on which the multitude of particular contents fight for hegemony". Para que uma particularidade se torne hegemônica, ela precisa atuar como ponto nodal, ou seja, algo capaz de unir as diversas particularidades em torno de um mesmo interesse comum.

Sobre este aspecto, Mandiola (2010), utilizando Laclau e Mouffe como referência de análise, afirma que os ECG (denominado pela autora de CMS) são um significante vazio, um local para pluralidade e antagonismo entre as diversas abordagens teóricas. Somente atuando como um significante vazio, os ECG podem unir correntes tão heterogêneas sobre um mesmo rótulo. Para ela, algumas expressões linguísticas, tais como reflexividade, desnaturalização, antiperformatividade, às quais incluímos também emancipação, funcionam como metáforas que representam a falha de um sistema de significação ou linguagem, atuando como pontos nodais.

Vale destacar que o pós-estruturalismo é fuga e reação ao pensamento dialético de Hegel (2008), pensamento este que influenciou a dialética de Marx. Butler (2000) demonstra que, para Hegel, a universalidade é algo abstrato e metafísico, que exclui tudo que é específico ou particular de sua definição. Ou seja, Butler (2000, p. 17), ao interpretar Hegel (2008), estabelece que "Universality in its abstract form thus requires cutting the person off from qualities which he or she may well share with others, but which do not rise to the level of abstraction required for the term "universality"

O fato de o pós-estruturalismo definir a subjetividade, e, consequentemente, o sujeito, como algo fragmentado, descentrado, sem essência e origem (Calás \& Smircich, 1999; Peters, 2000; Rolnik, 1997a; Souza, 2012), não o impossibilita de ação política. Contudo, o significado de emancipação não se fundamenta em grandes metanarrativas emancipadoras, mas sim em múltiplas contingencialidades e particularidades. Aliás, muitos pós-estruturalistas preferem usar o termo práticas de liberdade (Foucault, 2004a), liberação (Mandiola, 2010) e emancipações (Laclau, 1996), ao invés de emancipação no singular. 
Para o pós-estruturalismo, qualquer projeto emancipatório não deve pretender libertar o homem de ideologias dominantes que seriam prejudiciais a ele (Alvesson \& Willmott, 1996), pois, apesar de, por exemplo, Foucault (1979) estudar o poder, isso não significa que, na concepção de poder contida neste autor, haja uma ideologia dominante que atuaria como elemento principal da construção subjetiva de maneira a reprimir a autonomia e a liberdade, produzindo dominação e alienação - para Foucault (1979) o poder atua de forma muita mais positiva do que repressiva. Aliás, conforme Souza e Garcia (2007) salientam, Foucault não trabalha com conceitos de dominação e ideologia, e não o faz exatamente para não cair na relação causa-efeito composta pela tríade ideologia-dominação-alienação, na qual a ideologia seria produtora de dominação que, por sua vez, alienaria o homem, cabendo aos pensadores críticos atuar contra tais dominação e alienação por meio de processos emancipatórios universais. Aliás, Foucault (1979, p. 71) afirma que o que "os intelectuais descobriram recentemente é que as massas não necessitam deles para saber; elas sabem perfeitamente, claramente, muito melhor do que eles".

O projeto emancipatório, quando entendido como libertação do homem de ideologias prejudiciais a ele, faz-nos pressupor que, em algum momento da história, o homem não era constituído por relações de poder, e que diversos processos históricos acabaram o alienando, sendo que alienação não significa produção de falsa consciência, mas principalmente a perda de rumo em direção ao caminho que nos levaria ao bem estar coletivo e ao progresso emancipatório. Para o pósestruturalismo, o homem não tem origem ou essência, assim sendo, não existiu em nenhum momento da história do homem um ser puro, autônomo e livre das relações de poder (Foucault, 2002a, 2002b, 2004a; Guattari, 1992; Rolnik, 1997a, 1997b), e uma tentativa de resgate desta essência é algo impossível pela sua própria inexistência.

Um ponto crucial de análise na relação entre subjetividade e emancipação é a razão. Apesar da crítica que a Teoria Crítica Frankfurtiana faz ao Iluminismo (Paula, 2009), ela ainda mantém sua crença na razão e no progresso Iluminista, sendo que a razão ocupa um papel preponderante na emancipação, pois é uma certa dose de autonomia e a capacidade de reflexão dos sujeitos por meio da razão que torna possível o processo emancipatório (Alvesson \& Willmott, 1992; Paula, 2009). Como para o pós-estruturalismo não existe um autor ou um ser racional capaz de refletir com certa autonomia para criar projetos emancipatórios, a razão é colocada em cheque, e o que é classificado como racional, ou não, é visto como fruto de processos que envolvem relações de poder na sua busca pela constituição de verdades. Não é à toa que Foucault (1972) dedicou-se a estudar a loucura. Ele o fez para mostrar que não somos seres tão racionais como imaginamos que somos, e a classificação do que é loucura se transforma a todo o momento ao longo da história, de acordo com as relações de poder hegemônicas de cada época, servindo, a partir da emergência do pensamento Iluminista, como um dispositivo de poder para delimitar e classificar o que é normal em detrimento do anormal. Como Foucault (2001) mesmo destaca, os anormais somos nós. Conforme já exposto, o que sempre interessou a Foucault é a constituição histórica das diferentes formas de sujeitos em relação aos jogos de verdade que os constituem. Assim, o poder não é exterior à verdade, ou seja, toda racionalidade é permeada e transpassada por relações de poder para que possa ser considerada verdade.

Nesse sentido, o pós-estruturalismo evita modelos prescritivos de como os sujeitos devem se constituir e julgamentos de valor sobre qual seria a melhor e a mais correta maneira de se viver. Por exemplo, para o pós-estruturalismo, a ética é apenas uma expansão das diversas e múltiplas formas de subjetividades possíveis. Desse modo, contrariamente aos grandes projetos emancipatórios, o pósestruturalismo não pretende apontar uma direção para onde os sujeitos deveriam caminhar, pois entende que as possibilidades são múltiplas e relativas a diversas subjetividades existentes em um determinado contexto histórico, cultural, social, político, religioso e econômico, dentre outros elementos. Vale salientar novamente que Foucault (2004a), em seu momento de análise ética, denominado pelo autor de cuidado de si, não acredita na possibilidade de uma forma geral de liberação, pois isso seria reafirmar que existe uma natureza e uma essência humana que foi ofuscada e alienada por mecanismos repressivos ao longo da história.

Alvesson e Willmott (1992) tentaram mesclar Teoria Crítica com Pós-estruturalismo, pela via do que chamaram de microemancipação. Para os autores, a microemancipação "é focada em atividades 
concretas, formas e técnicas que oferecem não somente os meios de controle, mas também os objetos facilitadores de resistência como veículo de liberação" (Alvesson \& Willmott, 1992, p. 446). Segundo Alvesson e Willmott (1992), a diferença entre emancipação e microemancipação está em ênfase. Enquanto a microemancipação enfatiza os movimentos parciais e temporários que se desconectam das diversas formas de opressão hegemônicas, a emancipação reforça os movimentos sucessivos na direção de um estado pré-determinado de liberação: "Esta visão micro da emancipação difere marcantemente da concepção tradicional de uma transformação de mão única da consciência entre 'falso' ou 'verdadeiro' com o elemento crucial na mudança de uma ordem social opressiva" (Alvesson \& Willmott, 1992, p. 447).

Alvesson e Willmott (1996) citam, para ilustrar o processo emancipatório, a abolição dos escravos. Contudo, a libertação dos escravos é vista por Foucault apenas como uma prática de liberação, pois ela não diz respeito à definição de práticas de liberdade que serão necessárias para que os escravos possam estabelecer um cuidado de si, ou seja, formas aceitáveis e satisfatórias de existência. Diferentemente da concepção de uma melhor e correta maneira de se viver, indicada pelos teóricos críticos, no pós-estruturalismo as formas aceitáveis e satisfatórias de existência são múltiplas e diversas, apesar de serem finitas, sem uma referência absoluta ou mesmo estabilizada para o isolamento de um melhor. A existência dessa referência seria incoerente na medida em que é incapaz de ser fundada nas múltiplas subjetividades em seus microfluxos de construção assumidas na abordagem. Contudo, vale salientar que Willmott (2005), em seus últimos trabalhos, afasta-se de qualquer elemento contido na proposta de emancipação da Teoria Crítica de Frankfurt, aproximandose do pós-estruturalismo de forma mais acentuada, principalmente de Laclau e Mouffe (1987).

Vale destacar que Laclau acredita na emancipação. Contudo, emancipação tem um significado próprio em Laclau, que a difere do conceito contido na Teoria Crítica. Para Laclau (1996), a emancipação não pode ser vista como um processo de lutas que irá eliminar a opressão e nem como tendo uma essência a priori. Como afirma Willmott (2005), Laclau e Mouffe (1987) abandonam a ideia de que existe um dualismo entre agência e estrutura, em que a contradição entre as propriedades da ação e da estrutura prove a possibilidade de emancipação. Há uma rejeição em Laclau e Mouffe à crença de que a eliminação da opressão estrutural é precondição para a liberdade. Toda universalidade é incompleta e inacabada, da mesma forma só há possibilidade de hegemonia com a presença de um significante vazio e, se o "destino da emancipação está vinculado à constituição de um discurso universal, hegemônico, é nesse momento que ele poderia avançar em direção a uma sociedade mais justa" (Mendonça, 2008, p. 67). Contudo, "ele avança, mas não deixa de pagar o seu preço: a impossibilidade da emancipação" (Mendonça, 2008, p. 67).

Assim, o pós-estruturalismo, apesar das diferenças existentes entre seus autores em relação à emancipação e à utilização desse termo, acredita que emancipação só é possível se não estiver fundamentada em grandes projetos que estabeleceriam uma emancipação a priori. No lugar de uma emancipação universal e essencialista, o pós-estruturalismo aceita a pluralidade e a particularidade das demandas emancipatórias constituídas por contingências históricas. São essas particularidades que podem funcionar como ponto nodal para a sustentação da ação política na direção de intenções libertárias. Dessa forma, desde que se levadas em consideração as observações feitas a seguir sobre o significado de emancipação, universalidade e subjetividade, pode-se afirmar que o pós-estruturalismo também tem intenções emancipatórias, necessariamente no plural.

Primeiramente, emancipação não pode ser entendida como busca de uma origem ou essência do homem que foi perdida e corrompida no passado. Emancipação é algo múltiplo, heterogêneo, processual, contingencial, sempre envolto por poder e em constante movimento. Portanto, emancipação é um ponto-nodal e, assim sendo, um significante vazio, hegemonizado pelas particularidades que a contingenciam. Conforme afirma Laclau (2000b), para que uma particularidade se torne hegemônica, ela precisa atuar como ponto nodal, ou seja, algo capaz de unir as diversas particularidades em torno de um mesmo interesse comum. Desta forma, devido às particularidades que a constituem, só existe emancipação no plural, enfim, emancipações. 
O pós-estruturalismo não tem uma visão fundacionista nem essencialista do conceito de universalidade. Aliás, conforme já demonstrado, o pós-estruturalismo rompe com o pensamento dialético Hegeliano, no qual toda universalidade é vista como abstrata e excludente de tudo que é particular e específico. No pós-estruturalismo, não existe dicotomia ou antagonismo entre universalidade e particularidade, pois a universalidade somente pode existir na forma encarnada da particularidade. Assim, a visão de que o universal é sempre algo inacabado e incompleto acaba afirmando tanto a possibilidade quanto a impossibilidade da emancipação, por isso, as múltiplas emancipações são um processo e não um fim em si mesmas. Exatamente por excluir o particular é que o pós-estruturalismo não acredita em grandes movimentos, revoluções, práticas de liberação, metanarrativas libertadoras e soluções universais para a questão do sujeito.

Ainda em relação ao sujeito, o pós-estruturalismo não o entende como alienado, e a consequência disto é que, na ótica pós-estruturalista, as emancipações não significam desalienações e conscientizações pela razão, ou seja, não há o fim das relações de poder. Além disso, para o pósestruturalismo, a fragmentação do sujeito não é impossibilidade para suas emancipações, mas sua única possibilidade. O sujeito é, e sempre será, atravessado por relações de poder, relações estas múltiplas e variáveis, e não apenas efeito de uma estrutura, rompendo-se com a dicotomia estruturaagência.

Epstein (1995) faz duras críticas ao pós-estruturalismo. Para ela, qualquer tradição de pensamento que valoriza o discurso é irrelevante para o movimento político e deve ser rejeitada. Além disso, para Epstein (1995), o antiessencialismo, a diferença, a rejeição de metanarrativas, a visão construcionista e a rejeição em se proclamar uma verdade ou um valor universais é algo extremamente perigoso para qualquer movimento político. Fato que tornaria o pós-estruturalismo um beco sem saída para o pensamento da esquerda, afirmando sua impossibilidade de ação política.

Entretanto, Dempsey e Rowe (2004) demonstram a capacidade de ativismo político do pósestruturalismo, evidenciando ainda contribuições do pós-estruturalismo aos demais movimentos de esquerda. Os autores destacam que o pós-estruturalismo contribui para que: (a) os movimentos políticos e ativistas de esquerda rompam com a tendência de replicarem as formas de exclusão que intentam combater; (b) para resolver a tensão entre visão moral e estratégica, ou seja, como a justiça que motiva os movimentos e atrai outros para sua causa pode trabalhar para fortalecer uma visão política intransigente, visão esta normalmente requerida para o sucesso do movimento; e (c) para romper com a tendência de ativistas e movimentos na construção de uma essencialização de seus inimigos.

Além de Dempsey e Rowe (2004), o ativismo político do pós-estruturalismo pode ser evidenciado e entendido na obra de Laclau (2000a, 2005) ao analisar o populismo na Argentina e os movimentos antiglobalização em Seattle, na busca de Marchart (2007) pela diferenciação entre os conceitos de política e político, no debate de Newman (2005) sobre a capacidade de ação política dos movimentos antiglobalização, na análise de Butler (2000, 2010) dos movimentos feminista e sexuais, no debate de Alcadipani e Tureta (2009) sobre o que é crítico nos estudos organizacionais, na proclamação da intenção política emancipatória do pós-estruturalismo em Willmott (2005), dentre outros.

\section{Para Além da Conclusão}

Conforme afirmam Alcadipani e Tureta (2009), discussões sobre qual paradigma epistemológico é o mais verdadeiro ou o mais legítimo é algo corriqueiro dentro dos ECG. Entretanto, este artigo não foi escrito objetivando atribuir ao pós-estruturalismo o rótulo de verdade ou legitimidade em detrimento das outras possibilidades de estudos críticos. Aliás, dentro de uma visão pós-estruturalista, visão esta com a qual os autores deste artigo coadunam, não se acredita que exista uma corrente de pensamento que seja mais verdadeira que outra, enfim, não se pretendeu participar 
aqui de jogos de verdade ou das theory wars descritos, respectivamente, por Foucault e Dempsey e Rowe (2004). O que se intentou é contribuir para a reflexão sobre as tradições de pensamento que formam os estudos organizacionais críticos e suas diferenças epistemológicas, focando-se no pósestruturalismo e tendo como ponto principal de análise a busca pela emancipação e a concepção de subjetividade.

Dessa forma, o principal intento deste artigo foi contribuir com o rigor epistemológico no desenvolvimento de futuros trabalhos organizacionais que venham a utilizar como principal fundamentação teórica o pós-estruturalismo. Entretanto, isso não significa que não exista possibilidade de diálogo entre o pós-estruturalismo e outras correntes consideradas críticas nos estudos organizacionais, principalmente com a Teoria Crítica frankfurtiana - conforme demonstrado por Dempsey e Rowe (2004), existem diálogos entre essas abordagens. Aliás, parece-nos que as abordagens críticas constituem-se mutuamente por meio do diálogo existente entre elas. Assim sendo, acreditamos que, apesar dos particularismos de cada tradição teórica dos ECG, a emancipação atua como ponto nodal entre suas diversas abordagens, fato que constitui a emancipação como um significante vazio. Contudo, não existe emancipação no singular, mas emancipações no plural, que atuam como um significante vazio, ou seja, um local de pluralidade e antagonismos entre as diversas abordagens teóricas que constituem os ECG. Assim, existem diversas emancipações nos ECG e não somente uma. Portanto, as críticas ao pós-estruturalismo em relação à falta de ação política e proposta emancipatória não se justificam. O pós-estruturalismo é capaz de gerar ação política intentando promover emancipações. É claro que, conforme evidenciamos, o conceito de emancipação no pósestruturalismo tem suas particularidades internas tanto quanto em relação às demais abordagens contidas nos ECG.

Conforme demonstrou Laclau (1996, 2000b), só existe universalidade se houver particularidade. Por isso, o universal só existe quando se atua como um sempre vazio. Assim, o debate em torno da emancipação atua como um ponto nodal entre as diversas abordagens dos ECG e não apenas como ponto comum, tornando as particularidades contidas em suas abordagens algo hegemônico, universal, mas uma hegemonia/universalidade sempre precária, incompleta, inacabada, plural e antagônica. Portanto, não se pode falar em emancipação, mas sim em emancipações.

O sujeito para o pós-estruturalismo não é autônomo e nem determinado pela estrutura. Foucault (2004a) e Laclau $(1996,2000$ b) demonstram claramente a intenção do pós-estruturalismo em romper com a dicotomia estrutura-agência. O sujeito é, ao mesmo tempo, constituído e constituidor de sua subjetividade, contingenciada por discursos e relações de poder, inserida em uma rede complexa de narrativas e práticas instáveis. Assim, o pós-estruturalismo desestabiliza e quebra com a crença de que existiria uma relação causa-efeito entre ideologia-dominação-alienação. Além disso, o pósestruturalismo também prega o fim na dicotomia sujeito-objeto. Sendo a subjetividade descentrada e fragmentada, o sujeito não tem essência ou origem, pois, ao invés de ser origem, sua subjetividade está mergulhada em um duplo movimento de produção e efeito. O sujeito somente pode constituir-se eticamente quando há possibilidade de emergência de novas formas existências, denominado por Foucault (2004a) de práticas de liberdade.

Portanto, entender essas diferenças contribui para um maior rigor na realização de pesquisas organizacionais, tanto teóricas quanto teórico-empíricas. Além disso, o uso de autores epistemologicamente distantes como sendo autores que comunguem das mesmas ideias ocorre com grande frequência nos estudos organizacionais, ou seja, parafraseando Carrieri e Luz (1998), não existe pecado do lado de baixo do Equador.

Apesar da viabilidade e da possibilidade de diálogo entre o pós-estruturalismo e as demais abordagens críticas em estudos organizacionais, já salientada no início desta seção, acredita-se que, em relação ao projeto de emancipação, o pós-estruturalismo se afasta da Teoria Crítica, principalmente devido às diferenças existentes em relação às definições de sujeito, emancipação, universalidade e contingência. Por isso, não se acredita que seja coerente e possível a tentativa de mesclar Teoria Crítica e pós-estruturalismo na construção de um novo conceito de emancipação, como fizeram Alvesson e Willmott (1992), sem levar em consideração as particularidades dessas definições. 
Portanto, a contribuição final proposta neste artigo consiste em advogar que os estudiosos aproximem em seus estudos o pós-estruturalismo das demais abordagens, mas reconhecendo e se aproveitando das diferenças que dão sentido epistemológico a essa aproximação.

\section{Referências}

Adler, P., Forbes, L., \& Willmott, H. (2007). Critical management studies. Academy of Management Annals, 1(1), 119-179.

Alcadipani, R., \& Tureta, C. (2009). Perspectivas críticas no Brasil: entre a "verdadeira crítica" e o dia a dia. Cadernos EBAPE.BR, 7(3), 505-508. Recuperado de http://www.scielo.br/pdf/cebape/v7n3/a08v7n3.pdf. doi: 10.1590/S1679-39512009000300008

Alvesson, M., \& Willmott, H. (1992). On the idea of emancipation in management and organization studies. The Academy of Management Review, 17(3), 432-464. doi: 10.2307/258718

Alvesson, M., \& Willmott, H. (1996). Recasting emancipation in management and organization studies. In M. Alvesson \& H. Willmott (Orgs.), Making sense of management: a critical introduction (pp. 177-211). London: Sage.

André, M. (2010). Formação de professores: a constituição de um campo de estudos. Educação, 33(3), 174-181.

Braverman, H. (1987). Trabalho e capital monopolista: a degradação do trabalho no século XX (3a ed.). Rio de Janeiro: Guanabara

Butler, J. (2000). Restarting the universal: hegemony and the limits of formalism. In J. Butler, E. Laclau, \& S. Zizek (Orgs.), Contigency, hegemony, universality: contermporary dialogues on the left (pp. 11-43). London: Verso.

Butler, J. (2010). Problemas de gênero: feminismo e subversão da identidade. Rio de Janeiro. Civilização Brasileira.

Calás, M. B., \& Smircich, L. (1999). Past postmodernism? Reflections and tentative directions. The Academy of Management Review, 24(4), 649-671. doi: 10.2307/259347

Carrieri, A. P., \& Luz, T. R. (1998, setembro). Paradigmas e metodologias: não existe pecado do lado de baixo do equador. Anais do Encontro Nacional da Associação Nacional de Pós-Graduação e Pesquisa em Administração, Foz do Iguaçu, PR, Brasil, 22.

Davel, E., \& Alcadipani, R. (2003). Estudos críticos em administração: a produção científica brasileira nos anos 1990. Revista de Administração de Empresas, 43(4), 72-85. doi: 10.1590/S003475902003000400006

Dempsey, J., \& Rowe, J. K. (2004). Why Poststructuralism is a Live Wire for the Left. In D. Fuller \& R. Kitchin (Eds.), Radical theory/critical praxis: making a difference beyond the academy? (pp. 32-51).Vernon and Victoria, BC, Canada: Praxis (e)press.

Derrida, J. (1995). A escritura e a diferença. São Paulo: Editora Perspectiva.

Epstein, B. (1995). Why poststructuralism is a dead end for progressive thought. Socialist Review, 5(2), 83-119. 
Faria, J. H. (2009b). Consciência crítica com ciência idealista: paradoxos da redução sociológica na fenomenologia de Guerreiro Ramos. Cadernos EBAPE.BR, 7(3), 420-446. Recuperado de http://www.scielo.br/pdf/cebape/v7n3/a04v7n3.pdf. doi: 10.1590/S1679-39512009000300004

Faria, J. H. (2009a). Teoria crítica em estudos organizacionais no Brasil: o estado da arte. Cadernos EBAPE.BR, 7(3), 509-515. Recuperado de http://www.scielo.br/pdf/cebape/v7n3/a09v7n3.pdf. doi: $10.1590 /$ S1679-39512009000300009b

Faria, J. H., \& Meneghetti, F. K. (2007). O sequestro da subjetividade. In J. H. Faria (Org.), Análise crítica das teorias e práticas organizacionais (pp. 73-106). São Paulo: Atlas.

Foucault, M. (1972). História da loucura. São Paulo: Editora Perspectiva.

Foucault, M. (1979). Microfísica do poder. Rio de Janeiro: Graal.

Foucault, M. (1984). História da sexualidade: o uso dos prazeres. Rio de Janeiro: Edições Graal.

Foucault, M. (1996). A ordem do discurso. São Paulo: Edições Loyola.

Foucault, M. (1999). As palavras e as coisas: uma arqueologia das ciências humanas. São Paulo: Martins Fontes.

Foucault, M. (2001). Os anormais: curso no Collège de France. São Paulo: Martins Fontes.

Foucault, M. (2002b). Lacan, o "liberatore" da psicanálise. In M. Foucault (Ed.), Problematizações do sujeito: psicologia, psiquiatria e psicanálise (pp. 329-330). Rio de Janeiro: Forense Universitária.

Foucault, M. (2002a). Problematizações do sujeito: psicologia, psiquiatria e psicanálise. Rio de Janeiro: Forense Universitária.

Foucault, M. (2003). Conversação com Michel Foucault. In M. Foucault (Ed.), Ditos \& escritos IV. Estratégia, poder-saber (pp. 13-25). Rio de Janeiro: Forense Universitária.

Foucault, M. (2004a). A ética do cuidado de si como prática de liberdade. In M. Foucault (Ed.), Ética, sexualidade, política (pp. 264-287). Rio de Janeiro: Forense Universitária.

Foucault, M. (2004b). Uma estética da existência. In M. Foucault (Ed.), Ética, sexualidade, política (pp. 288-293). Rio de Janeiro: Forense Universitária.

Foucault, M. (2010). O sujeito e o poder. In H. Dreyfus \& P. Rabinow (Eds.), Michel Foucault: uma trajetória filosófica: para além do estruturalismo e da hermenêutica (2a ed. rev., pp. 231-249). Rio de Janeiro: Forense Universitária.

Fournier, V., \& Grey, C. (2006). Na hora da crítica: condições e perspectivas para estudos críticos de gestão. Revista de Administração de Empresas, 46(1), 71-86.

Grey, C., \& Willmott, H. (2005). Introduction. In C. Grey \& H. Willmott (Eds.), Critical managemet studies (pp. 1-20). Oxford: Oxford University.

Guattari, F. (1992). Caosmose: um novo paradigma estético. Rio de Janeiro: Editora 34.

Hales, C. P. (1986). What do managers do? A critical review of the evidence. Journal of Management Studies, 23(1), 88-115. doi: 10.1111/j.1467-6486.1986.tb00936.x

Hegel, G. W. F. (2008). Fenomenologia do espírito (5a ed.). Petrópolis, RJ: Vozes; Bragança Paulista: Ed. Universitária São Francisco. 
Jermier, J. M., \& Clegg, S. R. (1994). Critical issues in organization science: a dialogue. Organization Science, 5(1), 1-13.

Laclau, E. (1996). Emancipation(s). London: Verso.

Laclau, E. (2000b). Identity and hememony. In J. Butler, E. Laclau, \& S. Zizek (Orgs.), Contigency, hegemony, universality: contermporary dialogues on the left (pp. 44-89). London: Verso.

Laclau, E. (2000a). Nuevas reflexiones sobre la revolución de nuestro tiempo (2o ed.). Buenos Aires: Nueva Visión.

Laclau, E. (2005). La razón populista. Buenos Aires: Fondo de Cultura Económica.

Laclau, E., \& Mouffe, C. (1987). Hegemonia y estrategia socialista: hacia uma radicalización de la democracia. España: Siglo XXI.

Mandiola, M. (2010). Latin America's critical management? A liberation genealogy. Critical Perspectives on International Business, 6(2/3), 162-176. doi: 10.1108/17422041011049978

Marchart, O. (2007). Post-fundational political thought: political difference in Nancy, Lefort, Badiou and Laclau. Edinburgh: Edinburgh University Press.

Mendonça, D. (2008). A impossibilidade da emancipação: notas a partir da teoria do discurso. In D. Mendonça \& L. P. Rodrigues (Orgs.), Pós-estruturalismo e teoria do discurso: em torno de Ernesto Laclau (pp. 63-70). Porto Alegre: EDIPUCRS.

Newman, S. (2005). Power and politics in poststructuralist thougth: new theories of the political. London: Routledge.

Parker, M. (1995). Critique in the name of what: postmodernism and critical approaches to organization. Organization Studies, 16(4), 553-564. doi: 10.1177/017084069501600401

Parker, M., \& Thomas, R. (2011). What is a critical journal? Organization, 18(4), 419-427. doi: $10.1177 / 1350508411403535$

Paula, A. P. P. (2009, setembro). "O que o handbook não diz": novas considerações sobre teoria crítica e abordagens pós-modernas para estudos organizacionais. Anais do Encontro Nacional da Associação Nacional de Pós-Graduação e Pesquisa em Administração, São Paulo, SP, Brasil, 33.

Peters, M. (2000). Pós-estruturalismo e filosofia da diferença. Belo Horizonte: Autêntica.

Rolnik, S. (1997a). Toxicômanos de identidade: subjetividade em tempo de globalização. In D. S. Lins (Org.), Cultura e subjetividade: saberes nômades (pp. 19-24). Campinas: Papirus.

Rolnik, S. (1997b). Uma insólita viagem à subjetividade: fronteiras com a ética e a cultura. In D. S. Lins (Org.), Cultura e subjetividade: saberes nômades (pp. 25-34). Campinas: Papirus.

Rolnik, S. (1999). Novas figuras do caos: mutações da subjetividade contemporânea. In L. Santaella \& J. A. Vieira (Orgs.), Caos e ordem na filosofia e nas ciências (pp. 206-221). São Paulo: Face e Fapesp.

Saussure, F. (1993). Curso de lingüística geral. São Paulo: Cultrix.

Souza, E. M. (2012). Pós-modernidade nos estudos organizacionais: equívocos, antagonismos e dilemas. Cadernos EBAPE.BR, 10(2), 270-283. Recuperado de http://www.scielo.br/pdf/cebape/v10n2/v10n2a03.pdf. doi: 10.1590/S1679-39512012000200003 
Souza, E. M., \& Garcia, A. (2007). Um diálogo entre Foucault e o marxismo: caminhos e descaminhos. Revista Aulas, (3), 1-32.

Torffing, J. (1999). New theories of discourse. Oxford: Blackwell.

Willmott, H. (2005). Theorizing contemporary control: some post-structuralist responses to some critical realist questions. Organization, 12(5), 747-780. doi: 10.1177/1350508405055947 